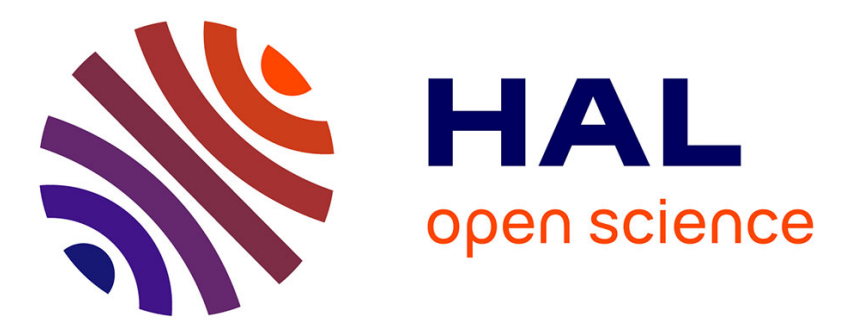

\title{
Cardiovascular risk factors in hypertensive patients born in Northern Africa and living in France
}

Charlotte Lepoutre-Lussey, Pierre-François Plouin, Olivier Steichen

\section{To cite this version:}

Charlotte Lepoutre-Lussey, Pierre-François Plouin, Olivier Steichen. Cardiovascular risk factors in hypertensive patients born in Northern Africa and living in France. Blood Pressure, 2010, 19 (2), pp.75-80. 10.3109/08037050903464741 . hal-01171831

\section{HAL Id: hal-01171831 \\ https://hal.sorbonne-universite.fr/hal-01171831}

Submitted on 6 Jul 2015

HAL is a multi-disciplinary open access archive for the deposit and dissemination of scientific research documents, whether they are published or not. The documents may come from teaching and research institutions in France or abroad, or from public or private research centers.
L'archive ouverte pluridisciplinaire HAL, est destinée au dépôt et à la diffusion de documents scientifiques de niveau recherche, publiés ou non, émanant des établissements d'enseignement et de recherche français ou étrangers, des laboratoires publics ou privés. 
Title: Cardiovascular risk factors in hypertensive patients born in Northern Africa and living in France

Authors : Charlotte Lepoutre-Lussey ${ }^{\mathrm{a}}$, MD, Pierre-François Plouin ${ }^{\mathrm{a}}$, MD, PhD, Olivier Steichen $^{\mathrm{b}}$, MD

aAP-HP, Hôpital Européen Georges Pompidou, unité d'hypertension artérielle, 20 rue Leblanc, 75908 Paris cedex 15; Université Paris Descartes, Faculté de Médecine, Paris.

${ }^{b}$ AP-HP, Hôpital Tenon, service de médecine interne, 4 rue de la Chine, 75020 Paris; Université Pierre et Marie Curie-Paris6, Faculté de Médecine, Paris.

Corresponding author: Olivier Steichen

Service de médecine interne, hôpital Tenon, 4 rue de la Chine, 75020 Paris, France.

Tel. (+33) 1560166 11. Fax (+33) 156017082

Email: olivier.steichen@tnn.aphp.fr

Running title: CVRF in hypertensive Northern Africans living in France

Conflict of interest: None 


\begin{abstract}
Northern Africans constitute one of the largest immigrant groups in France; however, limited data are available on their cardiovascular risk factors. We carried out a retrospective cross-sectional study in a French hypertension unit, comparing 719 patients born in Northern Africa to 3558 controls born in Europe, individually matched for age and sex. Using a Bonferroni adjusted $\alpha$-level $=0.001$, we found no significant difference between the groups for blood pressure levels, antihypertensive treatment, prevalence of target organ damage or the proportion of patients with secondary hypertension. However, patients of both sexes born in Northern Africa were less likely to take regular physical exercise than their controls. In addition, women born in Northern Africa were less often current or former smokers than their European counterparts $(19.9 \%$ vs. $30.5 \%$, p <0.001), but had a higher body mass index (28.5 vs. $26.8 \mathrm{~kg} / \mathrm{m} 2, \mathrm{p}<0.001)$ and a higher prevalence of diabetes $(19.1 \mathrm{vs} .8 .9 \%, \mathrm{p}<0.001$ after adjusting for BMI). These results suggest that targeted lifestyle interventions, including regular physical exercise, could be proposed to prevent weight gain and decrease the incidence of diabetes in hypertensive women born in Northern Africa and living in western countries.
\end{abstract}

\title{
KEYWORDS
}

Northern Africa; France; Hypertension; Diabetes Mellitus; Obesity; Dyslipidaemia. 


\section{INTRODUCTION}

The prevalence of hypertension is about $30 \%$ in Northern Africa [1-4]. Urbanisation seems to have contributed to the emergence of abdominal obesity, hypertension and diabetes in these countries [1].

Migrants from Northern Africa constitute $30 \%$ of all immigrants living in France; they represent $3 \%$ of the total population and $5 \%$ of the population in Paris and its suburbs [5]. Natives from Northern Africa living in France share several cultural characteristics with those living in their original country such as ancestry, language, religion and dietary habits. For instance, Méjean et al. showed that Tunisian migrant men living in southern France for 22 years on average had a healthier diet than localborn French controls, very close to the diet of non-migrant Tunisians, with a high fibre, low salt and low alcohol intake [6]. However, the diet of Tunisian migrants was more similar to that of French men in case of young age at migration or long residence in France [7]. On the contrary, the diet of Tunisian migrants remained like that of nonmigrant Tunisians in case of persistent social ties with the home country (language preference, house ownership or regular returns in Tunisia).

Few studies have been done in European countries to directly compare cardiovascular risk factors between hypertensive patients born in Northern Africa and those born in Europe. Data from the Netherlands suggest that the prevalence and pattern of hypertension and cardiovascular diseases differ between immigrants from Morocco living in the Netherlands and the native Dutch [8]. The management of hypertension may benefit from such findings to achieve individualised patient care; several guidelines are already taking the ethnic origin of the patient into consideration [9].

We determined characteristics associated with hypertension - such as duration and severity, complications, aetiology and associated cardiovascular risk factors - in patients born in Northern Africa and living in France referred to a hypertension unit, and compared them with those of European-born patients of similar age and sex.

\section{PATIENTS AND METHODS}

\section{Data retrieval and patient selection}

Data from patients referred to our hypertension unit were prospectively entered by physicians into an electronic health record database [10]. We analysed data from all patients born in Northern Africa (Algeria, Morocco, Tunisia, Egypt and Libya) or Europe who attended consultation for the first time between 01/01/2000 and $12 / 31 / 2006$. Patients were classified by the self-reported country of birth. We excluded patients with normal blood pressure without antihypertensive therapy and French patients born in the Caribbean.

The following data were collected during the first outpatient visit: age, sex, smoking habits, sports activity, history of hypertension, diabetes or dyslipidaemia, past medical history of stroke or coronary artery disease, body mass index (BMI), blood pressure (BP), Sokolow index and dipstick proteinuria. Treatment score was defined as the number of different antihypertensive drug classes prescribed to the patient.

In order to look for secondary hypertension and thoroughly assess target organ damage, hospitalisation was proposed to patients matching at least one of the following criteria: hypertension onset younger than 40 years old; resistant (BP $>140 / 90 \mathrm{mmHg}$ on three or more antihypertensive drugs including a diuretic) or severe (BP > 180/110 
$\mathrm{mmHg}$ ) hypertension; or hypertension associated with serum potassium $<3.9 \mathrm{mmol} / \mathrm{l}$ (or $<3.6 \mathrm{mmol} / \mathrm{l}$ if on thiazide or loop diuretic). Additional data were collected in these patients during hospitalisation: fasting plasma glucose, blood lipid levels, serum creatinine, left ventricular mass index determined by echocardiography if indicated, and the nature of hypertension (essential or secondary).

\section{Measurements and diagnostic criteria}

Trained nurses used a validated semi-automatic manometer (Omron 705CP) to measure BP. Three measurements were obtained in the sitting position, with a fiveminute rest between each. Office BP was taken as the average of the second and third measurements, as previously described [11]. We used the MDRD (Modification of Diet in Renal Disease) equation to estimate the glomerular filtration rate (GFR) [12]. An estimated GFR repeatedly lower than $60 \mathrm{ml} / \mathrm{min} / 1.73 \mathrm{~m}^{2}$ indicates chronic kidney disease; on the other side, reporting numeric values for estimated GFR higher than 60 $\mathrm{ml} / \mathrm{min} / 1.73 \mathrm{~m}^{2}$ is not recommended, because the impact of creatinine measurement error increases significantly above this value [13]. We therefore categorised estimated GFR in two categories: lower and higher than $60 \mathrm{ml} / \mathrm{min} / 1.73 \mathrm{~m}^{2}$. Left ventricular mass was calculated using the ASE (American Society of Echography) convention formula and indexed by body surface area [14].

Our screening methods and the criteria we used for diagnosing secondary forms of hypertension (primary aldosteronism, renovascular hypertension and parenchymal renal disease) were in accordance with institutional guidelines and have been described previously $[15,16]$. Briefly, primary aldosteronism was considered to be present if the aldosterone to renin ratio obtained in standardised conditions was at least $64 \mathrm{pmol} / \mathrm{mIU}$ (107 pmol/ng) in two separate measurements, along with a plasma aldosterone level over $500 \mathrm{pmol} / \mathrm{l}(18 \mathrm{ng} / \mathrm{dl})$ in the supine position or $550 \mathrm{pmol} / \mathrm{l}(20 \mathrm{ng} / \mathrm{dl})$ in the standing or sitting position, or an urinary aldosterone excretion over $63 \mathrm{nmol} / \mathrm{d}$ $(23 \mu \mathrm{g} / \mathrm{d})$. Renovascular hypertension was defined by renal artery stenosis exceeding a $60 \%$ reduction in luminal diameter (from atherosclerosis of fibromuscular dysplasia) on imaging. Hypertension was considered secondary to chronic kidney disease in patients with pre-existing parenchymal renal disease, indicated by an estimated glomerular filtration rate $<60 \mathrm{ml} / \mathrm{min} / 1.73 \mathrm{~m}^{2}$ or proteinuria.

\section{Statistical analysis}

Up to five European controls per Northern African case were individually matched for age $( \pm 1$ year) and sex. Univariate conditional logistic regression was used for matched analyses. The Wald test was used to test statistical significance. Continuous variables were not categorised for regression studies. Conformity to a linear gradient was graphically checked and polynomial or logarithmic transformations were performed when necessary. Interaction between sex and other variables was systematically checked and, when significant, the results for women and men are presented separately. As about fifty univariate comparisons between Northern-Africans and Europeans were planned (32 variables and two comparisons for some of them) without prior hypotheses to be tested, the significance threshold for these comparisons was adjusted by the Bonferroni method to $0.05 / 50=0.001$. When significant differences were observed between African and European patients, multivariable conditional logistic regression was performed to adjust for potential confounders. Statistical analyses were performed with Stata 8.2 (StataCorp, College Station, Texas, USA). 


\section{RESULTS}

Data were collected for 719 patients born in Northern Africa (334 women and 385 men) and a control sample of 3558 Europeans patients individually matched for age and sex (up to five European patients for each patient born in Northern Africa, comprising 1660 women and 1898 men). Countries of birth for patients from Northern Africa were: Algeria $(n=399 ; 55.5 \%)$, Morocco $(n=167 ; 23.2 \%)$, Tunisia $(n=118$; $16.4 \%)$, and Egypt $(\mathrm{n}=35 ; 4.9 \%)$. No patient was born in Libya. Most of the patients born in Europe were metropolitan French ( $\mathrm{n}=3349 ; 94 \%)$.

\section{Data collected during the first outpatient visit}

Characteristics of the whole study population are displayed in Table 1. Regarding the comparison between Northern Africans and European hypertensive, a statistically significant interaction was found between sex and the following variables: history of diabetes, diabetes treatment, history of smoking, duration of hypertension, and BMI (Table 1 and Figure 1).

Hypertension was slightly more recent in Northern African men (earlier referral). There were no statistical differences in blood pressure or treatment score at the first outpatient visit. Similar antihypertensive regimens were prescribed in both groups: renin-angiotensin system blockers were the most commonly used (60\% of the patients), followed by diuretics (52\%), calcium channel antagonists $(51 \%)$, betablockers $(43 \%)$ and centrally acting agents (18\%). The prevalence of dyslipidaemia was similar in both groups. Both men and women from Northern Africa were less likely to practice a sport than their European-born counterparts. Women born in Northern Africa, but not men, had higher BMI, a higher prevalence of diabetes and were less likely to have a history of smoking than their European counterparts. Diabetes prevalence was significantly associated with BMI in women born in Northern Africa with a diabetes odds ratio 1.47 [95\% CI: $1.17,1.85$ ] for each $5 \mathrm{~kg} / \mathrm{m}^{2}$ increase in BMI. The difference in the prevalence of diabetes in women, however, persisted after adjustment for BMI (adjusted p < 0.001).

The prevalence of dipstick proteinuria was slightly higher in patients born in Northern Africa. However, this did not reach statistical significance in univariate analysis $(\mathrm{p}=0.003$, with a significance threshold of $\mathrm{p}=0.001)$, and was explained by higher BMI and prevalence of diabetes in Northern Africans ( $\mathrm{p}=0.06$ after adjusting for these confounding variables). Coronary artery disease and stroke were equally prevalent in both groups.

\section{Data collected during hospitalisation}

The proportion of hospitalised patients was similar for Northern African- and European-born patients $(52.7 \%$ and $50.3 \%$, respectively; $\mathrm{p}=0.24)$. Regardless of their ethnic origin, hospitalised patients, compared with non-hospitalised patients, were more often men ( 58 vs. $49 \%$; Chi-square p < 0.001 ), were slightly older ( 57.3 vs. 56.3 years; Mann Whitney $\mathrm{p}=0.005$ ), had higher blood pressure (systolic BP 159 vs. $140 \mathrm{mmHg}$; Mann Whitney $\mathrm{p}<0.001$ ) and higher treatment scores (2.6 vs. 2.2; Mann Whitney $\mathrm{p}<$ $0.001)$. They also had slightly higher BMI (27.7 vs. $27.3 \mathrm{~kg} / \mathrm{m}^{2}$; Mann-Whitney p < 0.001 ) and were more often diabetic (16 vs. 10\%; Chi-square $\mathrm{p}<0.001)$. Regarding the comparison between Northern Africans and European hypertensive, there was no 
statistically significant interaction between sex and any variables recorded during hospitalisation. Available data are presented in Table 2.

Mean fasting plasma glucose was slightly higher in hospitalised Northern African patients compared to hospitalised European patients, but the difference did not reach statistical significance (with a threshold of $\mathrm{p}=0.001$ ), and even less after adjusting for the higher BMI and prevalence of diabetes $(\mathrm{p}=0.24)$. The lower level of HDL-cholesterol in Northern African patients remained statistically significant after adjustment for BMI and diabetes $(\mathrm{p}<0.001)$. The estimated glomerular filtration rate and left ventricular mass index were similar in Northern African and European patients. The prevalence of secondary hypertension was similar in both groups and there was no significant difference in the distribution of hypertension subtypes.

\section{DISCUSSION}

\section{Comparison with other studies and interpretation of the results}

Hypertension is more severe in certain ethnic groups such as African-Americans or patients born in sub-Saharan Africa than in patients from European origin [17-19]. Despite Northern Africans accounting for one of the largest immigrant groups in Europe, and particularly in France, there are only very limited data available on cardiovascular risk factors in this community. Findings obtained in Northern African studies do not apply to immigrants in Europe, because of the healthy immigrant effect [20]. Few studies have been conducted on immigrants from Northern Africa in Europe. A French survey compared self-reported health indicators in households whose head was of Northern-African origin with French-headed households [21]. The prevalences of obesity and diabetes were twice higher in women from Northern Africa than in French women, whereas the prevalence of current smoking was twice less. No differences were observed in men regarding obesity, diabetes and smoking. Agyemang et al. compared a group of 511 native Dutch subjects to a group of 433 Turkish immigrants and a group of 360 Moroccan immigrants [6]. The study participants were drawn from a representative subsample of the population from Amsterdam and thoroughly assessed. Hypertension was less prevalent among immigrants from Morocco than among the Dutch subjects, but Moroccan hypertensive women were less likely to be treated than their Dutch counterparts. Moroccan immigrants, especially women, were less likely to be current smokers than their Dutch counterparts. Women, and to a lesser extent men, from Morocco had a higher BMI than native Dutch. A greater proportion of Moroccan women than Dutch women were diabetic and a smaller proportion did sport. These results, observed in non-selected patients (with and without hypertension), are also consistent with our findings. The differences in cardiovascular risk factors that we observed in hypertensive patients thus seem to reflect similar differences found in the general population.

The higher prevalence of obesity and diabetes among hypertensive Northern African women may be related to differences in lifestyle (including sports activities and eating habits) and/or genetic susceptibility. Differences in lifestyle themselves may be related to cultural background, environment or socio-economical issues. For example, the same Dutch team found that Moroccan immigrants had a lower education level than native Dutch, and that hypertension in this ethnic group was associated with environmental stressors [22]. An epidemiological study showed that the prevalence of 
obesity is rapidly increasing in Morocco and Tunisia, more than half of adult women now being overweight or obese [23]. Urbanisation largely contributes to this trend, probably related to a sedentary lifestyle and changes in eating habits. Immigration from Northern Africa to industrialised countries like France could have similar consequences.

\section{Limitations}

This study has several limitations related to its retrospective and cross-sectional design. Data were collected prospectively for patient care, but not exhaustively. Additional variables not recorded for routine patient care - like immigration date, economical and educational status - may have been useful to explain the observed differences. Our analyses are potentially subject to confounding by factors inadequately controlled for by matching and adjustment.

This study is hospital-based, leading to an obvious selection bias: many hypertensive patients born in Northern Africa or Europe and living in France are not referred to a hypertension unit. Moreover, our unit is highly specialised in the diagnostic and therapeutic approach of secondary hypertension. The characteristics of this study population are thus unrepresentative of the whole population of hypertensive patients living in France. However, referral to a hypertension unit is unlikely to have generated a differential bias between the two ethnic groups, given that primary and hospital care is equally accessible to nearly everybody living in France. Moreover, our results show that patients born in Northern Africa are referred to a hypertension unit at the same stage of disease (similar duration of hypertension, BP levels and treatment scores) as native Europeans. Observed differences are therefore likely to reflect true differences between hypertensive patients from these two ethnic groups taken at the same stage of disease. Whether the same differences exist among patients with less severe hypertension is still uncertain.

\section{Research and clinical implications}

Further studies are needed to evaluate the prevalence and pattern of cardiovascular risk factors across the full spectrum of immigrants from Northern Africa and living in Europe, in specialised and primary care settings, or even at the general population level. These studies ought to explore the cultural, environmental, and socioeconomical factors that could explain the observed differences between immigrants from Northern Africa and native Europeans. The higher prevalence of obesity and diabetes in hypertensive women born in Northern Africa suggests that lifestyle improvement would be especially beneficial in this population and targeted actions should be considered. 


\section{REFERENCES}

1. Rguibi M, Belahsen R. High blood pressure in urban Moroccan Sahraoui woman. $J$ Hypertens 2007; 25: 1363-1368.

2. Temmar M, Labat C, Benkhedda S, Charifi M, Thomas F, Bouafia MT et al. Prevalence and determinants of hypertension in the Algerian Sahara. J Hypertens 2007; 25: 2218-2226.

3. Tazi MA, Abir-Khalil S, Chaouki N, Cherqaoui S, Lahmouz F, Srairi JE et al. Prevalence of the main cardiovascular risk factors in Morocco: results of a National survey, 2000. J Hypertens 2003; 21: 897-903.

4. Ibrahim MM, Rizk H, Appel LJ, el Aroussy W, Helmy S, Sharaf Y et al. Hypertension prevalence, awareness, treatment and control in Egypt. Results from the Egyptian National Hypertension Project (NPH). NPH investigative Team. Hypertension 1995; 26: 886-890.

5. Borrel C. Enquêtes annuelles de recensement 2004 et 2005. Insee Première 2006; 1098: 1-4.

6. Méjean C, Traissac P, Eymard-Duvernay S, El Ati J, Delpeuch F, Maire B. Diet quality of North African migrants in France partly explains their lower prevalence of diet-related chronic conditions relative to their native French peers. $J$ Nutr 2007; 137: 2106-2113.

7. Méjean C, Traissac P, Eymard-Duvernay S, Delpeuch F, Maire B. Influence of acculturation among Tunisian migrants in France and their past/present exposure to the home country on diet and physical activity. Public Health Nutr 2009; 12: 832-841. 8. Agyemang C, Ujcic-Voortman J, Uitenbroek D, Foets M, Droomers M. Prevalence and management of hypertension among Turkish, Morrocan and native Dutch ethnic groups in Amsterdam, The Netherlands: The Amsterdam Health Monitor Survey. $J$ Hypertens 2006; 24: 2169-2176.

9. Manna DR, Bruijnzeels MA, Mokkink HG, Berg M. Ethnic specific recommandations in clinical practice guidelines: a first exploratory comparison between guidelines from the USA, Canada, The UK, and the Netherlands. Qual Saf Health Care 2003; 12: 353-358.

10. Devries C, Degoulet P, Jeunemaitre X, Sauquet D, Morice V, Chatellier G et al. Integrating management and expertise in a computerised system for hypertensive patients. Nephrol Dial Transplant 1987; 2: 327-331.

11. La Batide-Alanore A, Chatellier G, Bobrie G, Fofol I, Plouin PF. Comparison of nurse- and physician-determined clinic blood pressure levels in patients referred to a hypertension clinic: implications for subsequent management. J Hypertens 2000; 18: 391-398.

12. Levey AS, Bosch JP, Lewis JB, Greene T, Rogers N, Roth D. A more accurate method to estimate glomerular filtration rate from serum creatinine: a new prediction equation. Modification of Diet in Renal Disease Study Group. Ann Intern Med 1999; 130: 461-471.

13. Myers GL, Miller WG, Coresh J, Fleming J, Greenberg N, Greene T et al. Recommandations for improving serum creatinine measurement: a report from the Labortory Working Group of the National Kidney Disease Education Program. Clin Chem 2006; 52: 5-18.

14. Devereux RB, Alonso DR, Lutas EM, Gottlieb GJ, Campo E, Sachs I et al. Echocardiographioc assessment of left ventricular hypertrophy: comparison to necropsy findings. Am J Cardiol 1986; 57: 450-458. 
15. Matrozova J, Steichen O, Amar L, Zacharieva S, Jeunemaitre X, Plouin PF. Fasting plasma glucose and serum lipids in patients with primary aldosteronism: a controlled cross-sectional study. Hypertension 2009; 53: 605-610

16. Plouin PF, La Batide-Alanore A, Fiquet-Kempf B, Rossignol P, Launay-Mignot P, Bobrie G. Hypertensions artérielles secondaires à des causes curables chez l'adulte.

Presse Med 2002; 31: 371-378.

17. Brown MJ. Hypertension and ethnic group. BMJ 2006;332:833-836.

18. Cruickshank JK, Mbanya JC, Wilks R, Balkau B, Forrester T, Anderson SG et al. Hypertension in four African-origin populations: current 'Rule of Halves', quality of blood pressure control and attribuable risk of cardiovascular disease. J Hypertens 2001; 19: 41-46.

19. Gombet T, Steichen O, Plouin P. Maladie hypertensive des personnes nées en Afrique subsaharienne adressées à un service de médecine spécialisé: étude transversale comparative. Bull Acad Natl Med 2007; 191: 1745-1754; discussion 1754-1745. 20. Marmot MG, Adelstein AM, Bulusu L. Lessons from the study of immigrant mortality. Lancet 1984; 1: 1455-1457.

21. Khlat M, Sermet C, Laurier D. La morbidité dans les ménages originaires du Maghreb, sur la base de l'enquête Santé de l'Insee, 1991-1992. Population (Paris) 1998; 53: $1155-1184$.

22. Agyemang C, van Hooijdonk C, Wendel-Vos W, Ujcic-Voortman JK, Lindeman E, Stronks K et al. Ethnic differences in the effect of environmental stressors on blood pressure and hypertension in the Netherlands. BMC Public Health 2007; 7: 118. 23. Mokhtar N, Elati J, Chabir R, Bour A, Elkari K, Schlossman NP, Caballero B, Aguenaou H. Diet culture and obesity in northern Africa. J Nutr 2001;131:887S-892S. 
Table 1: Characteristics of hypertensive patients born in Europe or in Northern Africa at their first outpatient visit.

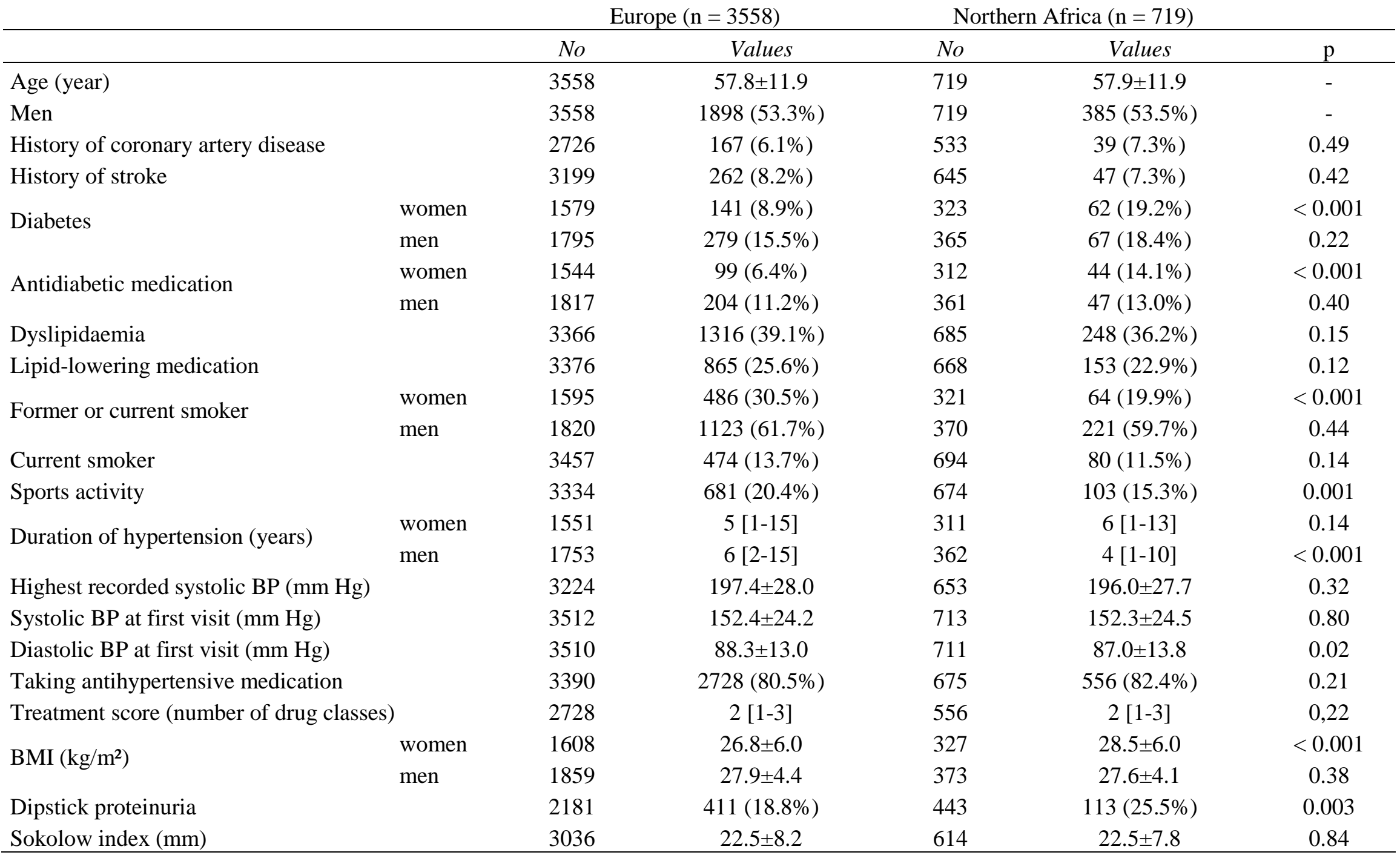

The number of patients available for analysis (No) is shown for each variable. Values are numbers of patients (percent), mean \pm standard deviation or median [interquartile range] and tested with conditional logistic regression (Wald test). BMI: body mass index; BP: blood pressure; RAS blockers: renin-angiotensin system blockers

(angiotensin-receptor blockers and angiotensin-converting-enzyme inhibitors). 
Table 2: Characteristics of hypertensive patients born in Europe or Northern Africa who were hospitalised after their outpatient visit

\begin{tabular}{|c|c|c|c|c|c|c|}
\hline & & \multicolumn{2}{|c|}{ Europe $(n=1790)$} & \multicolumn{2}{|c|}{ Northern Africa $(\mathrm{n}=379)$} & \multirow[t]{2}{*}{$\mathrm{p}$} \\
\hline & & No & Values & No & Values & \\
\hline Age (year) & & 1790 & $57.4 \pm 12.0$ & 379 & $57.0 \pm 11.6$ & - \\
\hline Men & & 1790 & $1031(57.6 \%)$ & 379 & $229(60.4 \%)$ & - \\
\hline Systolic BP at first visit (mm $\mathrm{Hg})$ & & 1772 & $158.5 \pm 24.5$ & 376 & $159.1 \pm 24.0$ & 0.96 \\
\hline Treatment score (n of classes) & & 1441 & $2.6 \pm 1.4$ & 307 & $2.7 \pm 1.3$ & 0.34 \\
\hline $\mathrm{BMI}\left(\mathrm{kg} / \mathrm{m}^{2}\right)$ & women & 751 & $27.0 \pm 5.8$ & 149 & $28.5 \pm 6.0$ & 0.02 \\
\hline \multirow{2}{*}{ Diabetes } & women & 743 & $80(10.8 \%)$ & 146 & $40(27.4 \%)$ & $<0.001$ \\
\hline & men & 1014 & $182(17.9 \%)$ & 224 & $45(20.1 \%)$ & 0.28 \\
\hline Fasting plasma glucose, $\mathrm{mmol} / \mathrm{l}$ & & 1614 & $6.0 \pm 1.6$ & 348 & $6.2 \pm 2.0$ & 0.003 \\
\hline Total cholesterol, mmol/1 & & 1631 & $5.3 \pm 1.1$ & 348 & $5.1 \pm 1.1$ & 0.007 \\
\hline HDL-cholesterol, mmol/l & & 1602 & $1.3 \pm 0.4$ & 341 & $1.2 \pm 0.4$ & $<0.001$ \\
\hline LDL-cholesterol, mmol/1 & & 1602 & $3.3 \pm 0.9$ & 341 & $3.2 \pm 1.0$ & 0.12 \\
\hline Triglycerides, mmol/l & & 1630 & $1.4 \pm 1.0$ & 347 & $1.5 \pm 1.0$ & 0.05 \\
\hline \multirow{2}{*}{ Creatinine, $\mu \mathrm{mol} / \mathrm{l}$} & women & 707 & $76.9 \pm 24.5$ & 142 & $77.7 \pm 30.1$ & 0.21 \\
\hline & men & 969 & $98.9 \pm 44.8$ & 215 & $102.1 \pm 39.8$ & 0.30 \\
\hline Estimated GFR $<60 \mathrm{ml} / \mathrm{mn} / 1.73 \mathrm{~m}^{2}$ & & 1676 & $292(17.4 \%)$ & 357 & $66(18.5 \%)$ & 0.51 \\
\hline \multirow{2}{*}{ Left ventricular mass, $\mathrm{g} / \mathrm{m}^{2}$} & women & 433 & $89.8 \pm 26.3$ & 82 & $91.3 \pm 25.0$ & 0.72 \\
\hline & men & 643 & $105.7 \pm 30.1$ & 150 & $104.3 \pm 29.0$ & 0.91 \\
\hline Secondary hypertension & & 1619 & $426(26.3 \%)$ & 331 & $97(29.3 \%)$ & 0.09 \\
\hline - Primary aldosteronism & & 1619 & $158(9.8 \%)$ & 331 & $42(12.7 \%)$ & 0.24 \\
\hline - Renal parenchymal disease & & 1619 & $99(6.1 \%)$ & 331 & $28(8.5 \%)$ & 0.02 \\
\hline - Renovascular disease & & 1619 & $138(8.5 \%)$ & 331 & $21(6.3 \%)$ & 0.52 \\
\hline
\end{tabular}

The number of patients available for analysis (No) is shown for each variable. Values are numbers of patients (percent), mean \pm standard deviation or median [interquartile range] and tested with conditional logistic regression (Wald test). BP: blood pressure; GFR: glomerular filtration rate 
Figure 1: Smoking history and prevalence of sports activity, obesity and diabetes by age, sex and ethnic origin.

\section{Current or former smoking}

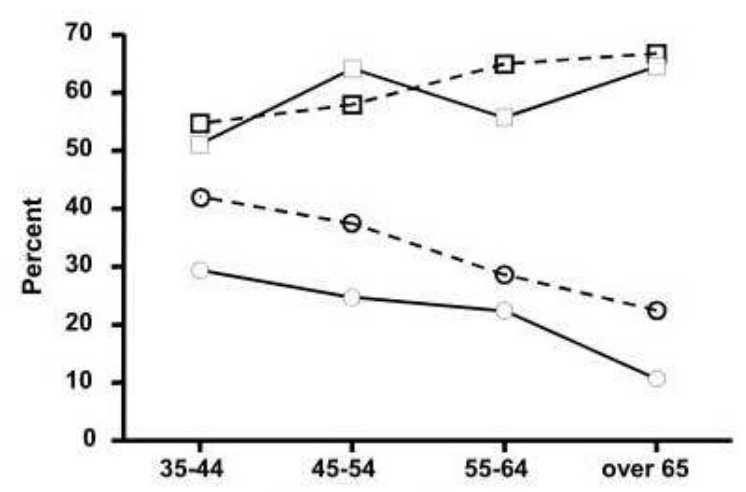

Diabetes

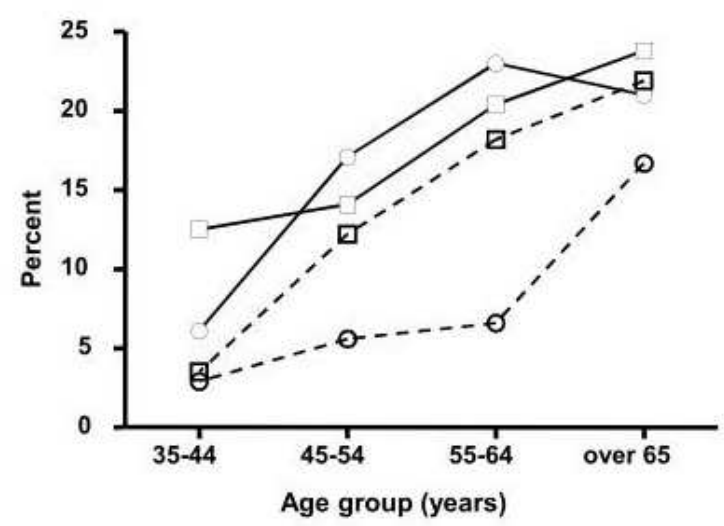

$\mathrm{BMI}>30 \mathrm{~kg} / \mathrm{m}^{2}$

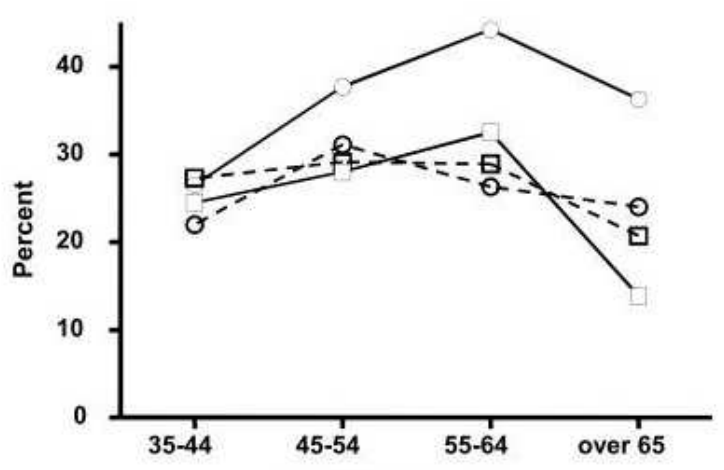

Sports activity

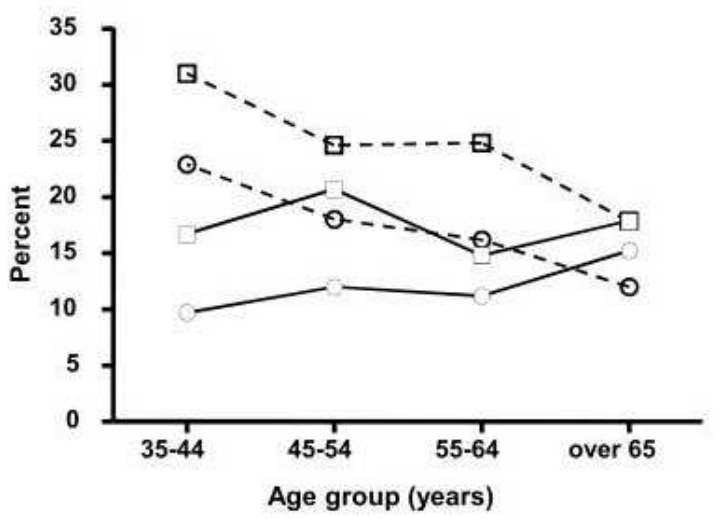

- North African men

-日. European men

- North African women

$-\Theta$ - European women 